\title{
EL SÍNDROME DE NARCISO Y EL AUTOR COMO AVATAR POSTORGÁNICO EN LAS NARRATIVAS DEL FUTURO: CARMEN BOULLOSA Y ÁLEX RIVERA
}

Teresa LÓPEZ-PELLISA

Universitat de Barcelona teresalopezpellisa@gmail.com

\begin{abstract}
A fin de comprender este fenómeno tan contemporáneo de exhibición de la intimidad —o la extimidad—, se impone una primera pregunta: ¿estas nuevas formas de expresión y comunicación que hoy proliferan en la Web - blogs y fotologs, redes de relaciones, webcams y videos caseros- deben consideras vidas u obras?
\end{abstract}

Paula Sibilia, La intimidad como espectáculo, 2008

$\mathrm{E}$ n este artículo propongo una lectura cibercultural de las narraciones El cielo de la Tierra (1997) y La novela perfecta (2006) de Carmen Boullosa en diálogo con la película Sleep Delaer (2008) de Álex Rivera. Se trata de tres textos de ciencia ficción en los que se reflexiona sobre la relación del ser humano con las nuevas tecnologías informáticas a partir de la suplantación del lenguaje escrito por un lenguaje de realidad virtual configurado a partir de imágenes y sensaciones. Tal y como dice Fernando Broncano en La melancolía del ciborg,

Los humanos no están inacabados, al contrario, sus técnicas, sus prótesis, los contextos de artefactos en los que evolucionaron sus ancestros homínidos les constituyeron como especie: no necesitan la técnica para completarse, son un producto de la técnica. Son, fueron, somos lo que llamaré seres ciborgs, seres hechos de materiales orgánicos y productos técnicos como el barro, la escritura, el fuego (2009: 19-20).

Por lo que la escritura y el lenguaje son tecnologías creadas por el ser humano, dividiéndose a los ciborgs (a los seres humanos) desde la escritura, tal y como defiende Fernando Broncano, entre quienes «tenían la prótesis de la lecto-escritura y quienes carecían de ella y, por tanto, del acceso al mundo culto. No es la obsolescencia, pues, el peligro, sino la exclusión» (2009: 42). En los textos que analizaremos se perciben dos posturas diferenciadas frente a los nuevos medios con los que contamos para disponer de esas prótesis de lecto-escritura que se han transformado en prótesis de lectovisualidad. Álex Rivera nos propone las herramientas cognitivo-culturales de la tecnología de la realidad virtual como una posibilidad de potenciar la identificación con el otro, frente a la propuesta distópica de Carmen Boullosa, en la que se perciben cierta melancolía y nostalgia ante la posibilidad de la desaparición de la cultura escrita que ha caracterizado la tradición. Por lo que cabría preguntarse 
si realmente la emergencia de la cultura digital y la literatura hipermedia supone la extinción de la cultura humanística y la idea tradicional del Humanus sapiens. Rosi Braidotti considera que «lo nuevo se crea revisitando y quemando lo viejo [...] ya que debemos asimilar el orden muerto antes de poder desplazarnos a un nuevo orden», pero también es importante recordar que el «anhelo nostálgico por un pasado supuestamente mejor es una respuesta apresurada y poco inteligente a los desafíos que nos plantea nuestro tiempo» (2004: 109 y 127). Todo texto narrativo tiene un significado simbólico dentro de la sociedad que lo produce y lo cierto es que la ciencia ficción, en concreto el ciberpunk, nos permite revisitar las contradicciones de nuestro tiempo.

\section{1. ¿Narrativas poshumanas?}

La escritora mexicana Carmen Boullosa desarrolla sus temores frente a la crisis del humanismo clásico en El cielo de la Tierra $(1997)^{1}$, al introducir un escenario distópico en el que la sociedad comienza a sufrir un proceso de degradación y deshumanización a partir de la pérdida de la capacidad del lenguaje, por lo que la narración y la memoria, se convierten en un acto subversivo de resistencia para conservar las particularidades que caracterizan al ser humano ${ }^{2}$. La teoría de la evolución de Charles Darwin nos permitió pensar en la posibilidad de que nosotros, como humanus sapiens, no fuéramos el último eslabón en la escala evolutiva. Actualmente los avances en biogenética y nanotecnología prometen transformaciones radicales en el cuerpo, la mente y las formas de vida humanas. Si la filosofía poshumanista se propone cambiar la forma radical de la existencia del ser humano a partir de la biogenética (y otras prácticas tecnológico-corporales), la propuesta de Carmen Boullosa en esta novela se centra en la modificación de la condición humana a partir de la desaparición del lenguaje. Lear, una de las protagonistas, vive en un mundo postnuclear en el que los seres poshumanos habitan en una burbuja sobre la Tierra ${ }^{3}$, nacen de manera artificial, se educan a través de la simulación, son inmortales, eternamente jóvenes y bellos tal y como soñarían Nick Bostrom (2011)

\footnotetext{
${ }^{1}$ En la novela nos encontramos con tres voces y niveles narrativos: 1) Hernando vive en el siglo XVI y ha escrito sus memorias en latín, ya que ha estudiado en un colegio franciscano que le ha hecho olvidar su lengua materna (el náhuatl), a partir de la implantación de la lengua colonial (español y latín); 2) Estela es una joven mexicana que viven en 1990 y está traduciendo las memorias de Hernando del latín al español; 3) Lear es una poshumana que habita en L'Atlantide tras una catástrofe que ha hecho inhabitable la Tierra, y es la encargada de recuperar los libros y la cultura de los que denominan los antiguos. Algunos de los temas centrales de la novela que nos interesa resaltar son la memoria y la pérdida de la identidad en relación con la pérdida del lenguaje.

${ }^{2}$ Francis Fukuyama considera que existe un factor $x$ que «es la esencia del hombre, el significado más básico de la condición humana» (1992: 244), compartido por todos los seres humanos y que nos hace iguales ante la ley, diferenciándonos del resto de los seres vivos. El factor $X$ del que habla Fukuyama no se puede reducir a la elección moral, la razón, el lenguaje, la sociabilidad, la sensibilidad, las emociones o la conciencia, que serían las bases de lo que se considera la dignidad humana: «Todas estas cualidades, combinadas en un todo humano, [son] las que conforman el Factor $\mathrm{X}$. Cada miembro de la raza humana posee una dotación genética que le permite convertirse en un todo humano; una dotación que distingue a un hombre, en esencia, de otros tipos de criaturas» (Fukuyama, 1992: 276). Pero el descubrimiento del código del genoma humano, así como los dígitos binarios que conforman el espacio digital, nos permiten incluir nuevas características, combinaciones y configuraciones de lo que podría definir a la humanidad y sus expresiones artísticas.

${ }^{3}$ Sobre las características de esta sociedad poshumana véase Brown (2010).

${ }^{4}$ El transhumanismo ha sido definido por Nick Bostrom - presidente de la Asociación Mundial de Transhumanismo (World Transhumanist Association [WTA]) y director del Future of Humanity Institute de la Universidad de Oxfordcomo «the intellectual and cultural movement that affirms the possibility and desirability of fundamentally improving the
} 


\section{Tropelías. Revista de Teoría de la Literatura y Literatura Comparada, 27 (2017) \\ El síndrome de Narciso y el autor como avatar postorgánico en las narrativas del futuro...}

y Savulescu (2012) que fuera el escenario ideal de la expansión del poshumanismo. Lear es la encargada de custodiar y leer los libros de la Historia de los Antiguos, y de ahí que sea la persona más afectada ante la noticia del programa de destrucción de la lengua: la Reforma del Lenguaje.

Podríamos considerar la novela de Carmen Boullosa como una distopía metafísica, debido a que uno de los puntos centrales de reflexión en texto es lo que se conoce en Filosofía del lenguaje como el «giro lingüístico» (véase Rorty, 1990). En el mundo poshumano de L'Atlàntide deciden suprimir el lenguaje porque consideran que es la única manera de alejarse del ser humano de la Historia y, por lo tanto, de alejarse «por siempre del mal» (1997: 112), ya que esa es la especie (la del Homo sapiens) que destruyó el planeta Tierra. Lear es consciente de las consecuencias que tendría una acción de tal magnitud y les advierte:

No les importa que todas las palabras vayan perdiendo poco a poco el eco que ilumina su sentido, porque están ocupados inventando un código de comunicación que las evite. Yo les digo que cualquier código aludirá al pasado, a la Historia, con la desventaja de que un código nuevo será manco, incapaz desde su origen, limitando el cerco de nuestra imaginación y el número de nuestras imaginaciones. El lenguaje fue manco también, lo acepto («la palabra ya, en sí, es un engaño, una trampa que encubre, disfraza y sepulta el edificio de nuestros sueños y verdades, todos señalados por el signo de lo incomunicable», escribió mi poeta), pero tenía el poder de invocar la memoria de los tiempos y las imaginaciones, y lo que fue, por la ley arbitraria de la realidad, imposible (1997: 19-20).

Lear considera que en la memoria y el recuerdo se encierra la única posibilidad de superviviencia ${ }^{5}$, y los sujetos poshumanos con los que convive creen que solo «sin lenguaje, sin gramática, podremos fundar un hombre nuevo» (1997: 117). Pero en la novela de Carmen Boullosa ese proceso de sustitución del lenguaje verbal por el lenguaje visual se produce a partir de una lobotomía que genera afasia ${ }^{6}$ en toda la población. Lear nos describe la transformación de la población como un proceso de involución y animalización: «mis divinos atlántidos, que algún día alcanzaron un estado de perfección que rebasaba cualquier sueño humano, al borrar de sus personas la palabra, han devenido en cerdos, comedores de carne de bebecitos muertos» (1997: 277). Así como la adquisición del lenguaje humanizaba a las bestias de La isla del Dr. Morau (1896) de H. G. Wells, la pérdida del mismo animaliza a los humanos del futuro ${ }^{7}$, pero, si tal y como rezaba el aforismo de Wittgenstein

human condition through applied reason, especially by developing and making widely available technologies to eliminate aging and to greatly enhance human intellectual, physical, and psychological capacities» (Bostrom, 2003: en línea).

${ }^{5}$ En la novela, Lear se pregunta qué son los libros: «¿Y por qué sí los libros? Porque los libros vencen la muerte de una manera muy distinta a como lo hemos conseguido los sobrevivientes. Desde el momento en que los libros fueron escritos, empezaron a parlotear con el pasado y con el futuro. Los libros siempre han sido memoria hacia otros tiempos, los que ya fueron, los que serán, los que no serán, los que no pudieron ser o no podrán ser o pudieron haber sido, mientras L'Atlàntide sobrevive decidida a asirse a un instante aislado, flotando en el agua estancada que impide la llegada de la muerte» (1997: 21). Y, ¿no podemos nosotros preguntarnos por qué no puede pervivir esa memoria en otro soporte con diversas tipologías lingüísticas?

${ }^{6}$ En este sentido es relevante mencionar la performance mecatrónica «Afasia» (1998) de Marcel·lí Antúnez. Se le diagnostica afasia a las personas que sufren alguna alteración del lenguaje debido a una lesión cerebral, y en esta performance, Marcel-lí Antúnez pretendía reflexionar, a partir del concepto del sujeto posmoderno como un personaje afásico, sobre la sociedad mass media actual en la que prima el lenguaje audiovisual frente al lenguaje escrito.

${ }^{7}$ La propuesta de Carmen Boullosa hace alusión al control que han ejercicio algunos sistemas ideológicos de la cultura escrita, conscientes del poder del lenguaje tal y como han reflejado las distopías políticas 1984 (1949) de George Orwell o Fahrenheit 451 (1953) de Ray Bradbury, y los terribles sistemas totalitarios que a lo largo de la historia quemaron libros, como en Berlín el 10 de mayo de 1933, en Chile el 14 de septiembre de 1973 o en Argentina el 26 de junio de 1980. 
«los límites de mi lenguaje son los límites de mi mundo», ¿no podrían convivir diferentes tipos de lenguajes que nos permitan comenzar a hablar de otro tipo de mundo? Si algo han puesto en evidencia las narrativas intermediales y transmedia es que podemos representar de diversos modos el mundo que conocemos. Sin necesidad de supresión o sustitución, la clave estaría en la convivencia y la convergencia (Jenkins, 2008). El mestizaje, la hibridación y las zonas liminares son los espacios naturales del cíborg, ya que, como advierte Fernando Broncano, somos «seres de la frontera» (2009: 26), hijos de la Malinche.

\section{2. ¿Narraciones de realidad virtual?}

La realidad virtual (RV) no es una tecnología que aparecerá en el futuro, ya que se trata de una tecnología del pasado, y, sin lugar a dudas, de una tecnología del presente. La tecnología de RV consiste en una simulación sintética (creada a base de gráficos computacionales - modelos lógicomatemáticos-), multisensorial y envolvente, con la que tenemos la capacidad de interactuar en tiempo real. Existen diferentes niveles de inmersión e interacción con este tipo de tecnología, desde lo que se conoce como RV de sobremesa, cuando nos introducimos con nuestro ordenador en entornos semiinmersivos como el ofrecido por algunos videojuegos, la Wii o Second Life. Hasta prototipos de inmersión fuerte que nos permiten sentirnos dentro de ese mundo artificial polisensorial gracias al uso de interfaces como los guantes de datos y los cascos esteroscópicos. La teórica que ha trabajado con mayor exhaustividad y lucidez las relaciones entre literatura y realidad virtual es Marie Laure-Ryan, a partir de las relaciones que establece entre la inmersión y la experiencia de lectura de los mundos ficcionales en los que el universo de ficción se convierte en una «realidad autónoma, independiente del lenguaje, poblada por seres vivos» (2004: 32). La lectura de un texto nos suscita incluso reacciones físicas, y la interactividad que caracteriza el medio digital, en sentido figurado, nos sirve para pensar en la relación entre el lector y el texto en la producción de significado, por lo que «durante siglos, los libros han sido la vanguardia en materia de realidad artificial» (Ryan, 2003: 109). Pero además, el espacio digital nos permite nuevas formas de expresión artísticas para las narraciones contemporáneas. La narrativa multimedia e hipermedia (véase Sánchez-Mesa, 2004, y Moreno, 2002) nos ofrece narraciones inmersivas e interactivas en las que la interacción del lecto-usuario es literal al tiempo que física, porque «la inmersión, en su sentido literal, es una experiencia corpórea [...] es imprescindible la proyección de un cuerpo virtual, o mejor aún, la participación de uno real, para que nos sintamos integrados en un mundo artístico» (Ryan, 2004: 39). Este tipo de participación es la que proponen Boullosa y Rivera.

En La novela perfecta, Carmen Boullosa recupera la preocupación por la extinción del lenguaje (escrito) que ya había planteado en El cielo de la Tierra, a partir de los procesos afásicos que podría ocasionar la influencia de los mass media en las interacciones comunicativas de la sociedad actual. En esta novela el ingeniero Paul le propone al escritor Alcorta una tecnología capaz de darle vida holográfica a sus historias, y así, poder «escribirlos» tan solo imaginando a sus personajes y describiendo sus tramas. Se trataría de un lenguaje multimedia de RV muy cercano al cinetexto, o al 


\section{Tropelías. Revista de Teoría de la Literatura y Literatura Comparada, 27 (2017) \\ El síndrome de Narciso y el autor como avatar postorgánico en las narrativas del futuro...}

ciberdrama del que nos hablaba Janet Murray en Hamlet en la holocubierta. En este caso, la imagen somete a la palabra y el lenguaje está mediatizado por la biología del organismo que funciona como un autor poshumano, tal y como sucede con las narraciones de Luz en la película Sleep Dealer. En La novela perfecta ${ }^{8}$ el lecto-espectador asiste en primera persona a un relato cuyos personajes puede oler y cuyas emociones puede sentir. La tecnología empleada permite al escritor transmitir su pensamiento directamente a la máquina, sin recurrir al lenguaje, tal y como Jaron Lanier preconizó cuando hablara de las posibilidades de la comunicación postsimbólica ${ }^{9}$.

¿Para qué matarte escribiendo [...] si luego nadie va a entender o apreciar? Y ¿quién tiene tiempo y espíritu hoy, como están las cosas, para de verdad LEER? Ya no va. Eso se acabó. Ir al cine se va poniendo también fuera de foco. El mundo virtual es a lo que hay que apostarle, pero sin menoscabo de la imaginación, inteligente y literaria. ¿Me sigues? [...]. Lo que te propongo es que hagamos tu novela tal cual es, tal como tú la ves en tu cabeza, tal como la cargas íntegra en tu imaginación, sin robarle una frase, un parlamento, una imagen, un sentimiento, una sensación, una idea, sin quitarle un pelo a su atmósfera... Idéntica a sí misma. El espejo fiel, y ya leído, de tu novela (Boullosa, 2006: 24).

El ingeniero protagonista cree que en un futuro próximo nos podremos comunicar con señales que harán innecesaria el habla, ya que tendremos medios más adecuados para expresar nuestros pensamientos y sentimientos, como proponía Kevin Warwick a partir de un chip intercutáneo implantado en conexión a sus sistema nervioso, el cual transmitía a su mujer de manera cromática sus estados de euforia o tranquilidad, a través de un collar que ella llevaba puesto ${ }^{10}$. En la novela se menciona explícitamente el trabajo de Warwick y las posibilidades de que un futuro convivamos con realidades mixtas (en las que realidad aumentada, realidad virtual y espacio real se combinen con naturalidad). Lederer, el ingeniero, propone que sus lectores lo lean tal y como «tú te lo imaginas sin que las palabras los separen de lo que tú estás queriendo decir, expresar, imprimir. Porque a mí que no me vengan con que las palabras son the real thing» (2006: 21). Y lo cierto es que con este tipo de holonarraciones el lector ya no debe «rellenar los huecos» (Iser) ni imaginar las escenas descritas. Tras el primer uso de la máquina, el escritor nos transmite su fascinación:

Voy a intentar ponerlo en palabras, pero, sin un ápice ya de fe. Serán palabras desilusionadas de sí mismas, que uso porque no me queda otra; comparadas con lo que vi, no serán nada. Porque eso que vi en el «laboratorio» de mi vecino no contenía toda la información de un golpe: desde el primer instante estaba ahí

\footnotetext{
${ }^{8}$ En un trabajo anterior analicé con detalle las relaciones entre La novela perfecta y la realidad virtual a partir de la patología de la metástasis de los simulacros (López-Pellisa, 2013). He diagnosticado como metástasis de los simulacros a la patología que se produce en algunos textos cuya temática gira en torno a la realidad virtual. La podemos detectar cuando analizamos la función del incremento de niveles de simulación, a través de lo que denomino «metadiégesis digital» (López-Pellisa, 2015). Con esta herramienta podemos diseccionar los diversos niveles de virtualidad y realidad virtual generados por máquinas digitales en los textos literarios y cinematográficos de ciencia ficción, partiendo de las teorías de Gérard Genette. A partir de su concepto de «metadiégesis», propongo el sintagma «metadiégesis digital», para hacer referencia a todos aquellos relatos en segundo grado que están generados por la tecnología digital. De este modo, siempre que los personajes de un texto desarrollen parte de la historia en un entorno de realidad virtual o en el ciberespacio, convivirán con diversos planos de realidad textual (real y digital), siendo la metadiégesis digital el nivel narrativo producido por la máquina.

9 Jaron Lanier sostiene que la realidad virtual proporciona un lenguaje natural que no necesita de códigos abstractos y encriptados como el que utilizamos en cada una de nuestras lenguas. Cree que el lenguaje sin símbolos nos permitirá comunicarnos sin una semántica restrictiva, ya que no percibimos el código (los símbolos binarios en este caso), sino los objetos que manipulamos de un modo natural como lo haríamos en el espacio real (véase Ryan, 2004: 83-84). Por ejemplo, si queremos hablar de una casa, mostramos una casa, sin necesidad de crear el símbolo de una casa.

${ }^{10}$ Información disponible en la página web de Kevin Warwick, en http://www.kevinwarwick.com.
} 
el ambiente, los personajes hechos, la tensión... ¡Era perfecto, perfecto, era lo que yo querría que fuera mi novela! Era una novela perfecta, porque todo era más que legible, porque se transmitía intacto lo imaginado, porque pasaba completo, cargado de emoción, color, luz, olor, presencia, tacto, vivo... ¡Vivo! Todo es inútil ahora. No puedo creer en mis palabras, en las palabras (2006: 42).

En la novela hay un «Ojo» que permite la multifocalización del videotexto según las preferencias del lecto-usuario que puede contemplar en 3D a cada uno de los personajes del relato. En «5 retos para el escritor del futuro» Doménico Chiappe nos habla de las posibilidades de la evolución del lenguaje a partir de un tipo de literatura que prescinda del texto (tal y como se prescindió de la oralidad y la gestualidad en el pasado).

Se trata de superar el texto como mediador único. Incluso se trata de superar todo aquello que intente mediar entre, por ejemplo, una fragancia y la fragancia misma. Con lo multimedia, la palabra escrita gana y pierde espacios. La entidad digital del libro contendrá y transmitirá, además de lo visual y lo audible, los olores y sabores, convirtiéndose así en más territorios para la literatura (Chiappe, 2015).

Esta propuesta literaria (o posliteraria) nos permite pensar en el libro virtual e hipermedia, pero en la novela de Carmen Boullosa este lenguaje intermedial y transmedia(tizado) se descontrola, y los personajes terminan asesinado al autor. La novela perfecta continúa con la línea marcada en El cielo de la Tierra cuando Estela decía: «Armaré una breve sucesión de imágenes como un preámbulo a la explicación que trato de hacer de la importancia que tiene para mí el manuscrito de Hernando. Tendrá un poco de videoclip, de lenguaje inconexo de imágenes, al que, en la televisión y el mal cine, nos hemos ido acostumbrando, imbecilizándonos» (1997: 33), quizás para criticar los nuevos lenguajes emergentes que combinan la tecnología digital con la audiovisual. Sea como fuere, se trata de una postura frente a las nuevas narrativas muy diferente a la propuesta por Álex Rivera en su película.

Sleep Dealer es una película posciberpunk dirigida en 2008 por Álex Rivera. Pero antes de realizar este largometraje, ya había planteado algunos de los temas de Sleep Dealer en el cortometraje Why ciberbraceros? (1997). Para comprender el tema central del cortometraje y de la película, debemos remontarnos al «Programa Bracero» que puso en marcha el gobierno de Estados Unidos y México en 1942 para llevar mano de obra mexicana a Estados Unidos. Se inició tras la Segunda Guerra Mundial debido a la falta de trabajadores (de brazos) en los campos norteamericanos para la recolección de la cosecha. El programa se alargó hasta la década de los 60, y consistió en una de las políticas migratorias que mayor efecto tuvo entre la comunidad étnica mexicana. Como política de propaganda frente a las demandas por explotación laboral y violación de los derechos humanos, este programa filmó un documental titulado Why Braceros? (1950) con el ánimo de concienciar a la población norteamericana de los beneficios que aportaba a la sociedad el flujo de trabajadores mexicanos. Con este precedente audiovisual, y tras leer en la revista Wired un reportaje sobre teletrabajo, Álex Rivera preparó Why Ciberbraceros? a partir de las posibilidades de la migración transfronteriza que propiciaba el teleempleo. El corto define lo que significa ciberbracero en español:

[...] ciberbracero es un trabajador que opera una computadora con los brazos y las manos. Pero en la jerga estadounidense, cyberbracero significa un trabajador que no presenta una amenaza para convertirse en 


\section{Tropelías. Revista de Teoría de la Literatura y Literatura Comparada, 27 (2017) \\ El síndrome de Narciso y el autor como avatar postorgánico en las narrativas del futuro...}

un ciudadano, y eso significa productos de calidad a bajo costo financiero y social para usted, el consumidor estadounidense (Rivera, 1997).

Para el cortometraje utilizó imágenes del documental de los años 50, además de la sobreimpresión de animación para ejemplificar el robot que el teletrabajador manipulaba con un joystick y un teclado, desde su casa, gracias a la telepresencia ${ }^{11}$. En Sleep Dealer el director desarrolla esta propuesta, incluyendo otras cuestiones relacionadas con las interacciones que ofrece la tecnología digital y la realidad virtual relacionadas con el cibersexo, la literatura y el ocio. La película presenta una fuerte crítica social a la problemática de la emigración mexicana en Estados Unidos y la explotación de los emigrantes. Memo se ve obligado a emigrar a Tijuana para trabajar como sleep dealer en una infomaquiladora, y necesitará de un coyotech para que le implante unos nodos del mercado negro, que le permitan conectarse a la red para poder trabajar en Estados Unidos, pero desde la frontera de Tijuana ${ }^{12}$ : «Este es el sueño americano. El trabajo sin los trabajadores». Por lo que estos sleep dealers ocupan cuerpos reales a través del poder que les otorga el ciberespacio para conectarse con el otro lado de una realidad que nunca podrán conocer físicamente: tan solo virtualmente. Estos cibertrabajadores pareciera que no tienen voz, y que podrían representar el concepto del sujeto subalterno de Spivak (2003), y es cierto, no son escuchados, no hablan, pero sí actúan. A partir del hackeo del sistema poscapitalista y de un agenciamiento de la tecnología subvierten el sentido y el uso de los nodos que los esclavizan en beneficio de su pueblo ${ }^{13}$.

Al margen de los procesos de tecnocolonialismo que se denuncian en la película, lo que nos interesa analizar en este trabajo es el tipo de narraciones del futuro que escribe Luz, la amiga y compañera de Memo, y la escritora de este relato. La tecnología que utiliza «TRUNODE. El mercado de memorias número uno del mundo», para que las personas puedan narrar sus recuerdos y vender sus relatos, es muy similar a la propuesta por Carmen Boullosa en La novela perfecta. En la película, Luz es una escritora que vende fragmentos de su memoria a través de una conexión biológica de su sistema

\footnotetext{
${ }^{11}$ Otras películas de ciencia ficción en las que se reflexiona sobre la inmigración serían Distrito 9 (2009) y Elysium (2013) dirigidas por Neill Blomkamp.

${ }^{12}$ La terminología relacionada con la inmigración ilegal en la frontera entre México y Estados Unidos se revisita desde la perspectiva tecnológica, por lo que el coyote se convierte en el coyotech (que facilita la biotecnología para poder trabajar al otro lado de la frontera), y la maquiladora se convierte en la infomaquila (para seguir haciendo referencia a las «maquiladoras» como centros de trabajo con regímenes fiscales excepcionales que fabrican productos que se exportan a bajo precio y cuyo capital depende de la inversión extranjera).

${ }^{13}$ Memo se ve obligado a emigrar a Tijuana porque un dron pilotado a través de telepresencia destruye su casa por error, provocando la muerte de su padre. Este dron defiende los intereses de la multinacional norteamericana que regula los suministros del agua en la zona (ya que una de las riquezas del futuro es el agua). Al llegar a Tijuana conoce a Luz, que le facilitará los nodos para poder trabajar en la infomaquiladora, y a su vez, ella contará el relato de Memo en TRUNODE para ganar algún dinero con la venta de sus historias. El piloto del dron que asesinó a su padre, al comprar las narraciones de Luz, se dará cuenta de las repercusiones de sus acciones y juntos utilizarán los nodos de la multinacional que tiene Rudy (el piloto) para conectarse a través de la red mexicana y destruir la presa para liberar el agua que necesita la población. Ruby, un soldado de origen mexicano, recupera su identidad a partir de la toma de conciencia de las holonarraciones de Luz (que alumbra a los dos personajes) y Memo (que representa la memoria). A partir del «hackeo colectivo» comparten sus conocimientos tecnológicos por el bien común a partir de una práctica hacktivista que muestra las esperanzas que ofrece el mundo digital, porque: «La frontera está cerrada...pero la red está abierta». Sobre un análisis detallado de la película desde esta perspectiva véase García (2012) y Brescia (2015). Esta lectura nos permite pensar en las posibilidades participativas, hiperpolíticas y activistas de las nuevas tecnologías a partir de las narrativas contemporáneas.
} 
nervioso con la red, para ofrecer nanoinformación hipermedia de realidad virtual. El receptor-usuario consume este youtube de realidad virtual, comprando experiencias polisensoriales de estos escritores profesionales, que, a modo de dietario de blog del futuro, narran sus testimonios a través de esta comunicación possimbólica.

Jaron Lanier, padre de la RV, entendía que esta tecnología crearía una nueva conciencia social y nos ofertaría nuevos modos de memoria exenta, porque consideraba que el entorno digital se convertiría de este modo en una base de datos de nuestras experiencias virtuales a la que podríamos acudir en cualquier momento, para recordar cualquier sensación o imagen. Frente a las generalizadas críticas sobre si la realidad virtual es el nuevo opio del pueblo (Quéau, 1995: 32), Lanier argumenta que no se trata de una tecnología escapista, ya que nos permite una mirada renovada sobre el mundo físico tras la inmersión, así como una posibilidad de incrementar nuestras capacidades empáticas y tomar conciencia social a partir de nuestra interacción en primera persona con las memoriasautobiográficas de otras personas, tal y como sucede con las narraciones de Luz, o tal y como propone la tecnología de la máquina «To be another» ${ }^{14}$.

\section{El síndrome de Narciso y el autor como avatar postorgánico}

La tecnología ofrecida por La novela perfecta le permite al escritor crear ficciones que parezcan reales (la realidad) a partir de los efectos de hiper(verosimilitud)realismo que permite la máquina de $\mathrm{RV}$ al crear estas holonarraciones. La sofisticación de este hiperlenguaje multimedia lleva hasta el extremo las posibilidades de la representación mimética iniciada con las prácticas artísticas de la época clásica, revitalizadas en el Renacimiento, y exacerbadas con el Naturalismo en el siglo XIX. Cuando el escritor protagonista contempla por primera vez a Ana, el personaje de su nueva novela, nos dice:

Ahí estaba: no tenía comparación ni con un lienzo ni con la pantalla, porque tenía toda la textura de lo real sin el resplandor de la luz artificial. Podría ser como una pintura, pero era más que una hiper-realista, más también que una fotografía: era literalmente un trozo de realidad con la salvedad de que representaba algo totalmente irreal, un trozo de realidad que no obedecía las órdenes de lo real, que se había alborotado, que se había deshecho y reconformado de una manera anómala (Boullosa, 2006: 122).

Pero en la época de los simulacros y la espectacularización mediática de la vida a través de los realty shows y las redes sociales, parece que la crisis entre realidad, verdad y ficción se ha acentuado. El ingeniero de La novela perfecta considera que «Las palabras son de lo mejor que hay para mentir o para hacer poemas. Pero no para retratar con precisión la verdad; no para narrar; no para explicar» (Boullosa, 2006: 23), planteando una reflexión sobre un cambio que ya se está produciendo en la narrativa contemporánea ¿o del futuro?, en la que la tecnología de RV ofrece cinetextos más reales que la realidad. Paula Sibilia considera que en la cultura contemporánea hay una «sed de veracidad» que busca lo «realmente real», pero no a partir de experiencias ficcionales que parecen reales, sino de experiencias auténticas de la «intimidad ajena» (2008: 221). Y es cierto que las redes sociales y el auge

\footnotetext{
${ }^{14}$ Toda la información sobre este proyecto y sus instalaciones en http://www.themachinetobeanother.org.
} 


\section{Tropelías. Revista de Teoría de la Literatura y Literatura Comparada, 27 (2017) \\ El síndrome de Narciso y el autor como avatar postorgánico en las narrativas del futuro...}

de las producciones biográficas, autobiográficas y autoficcionles (tanto en la literatura como en el cine) revelan ese interés creciente por conocer la vida real del otro, por muy banal que esta se muestre:

Si la paradoja del realismo clásico consistía en inventar ficciones que pareciesen realidades, manipulando todos los recursos de verosimilitud imaginables, hoy asistimos a otra versión de ese aparente contrasentido: una voluntad de inventar realidades que parezcan ficciones. Espectacularizar el yo consiste precisamente en eso: transformar nuestras personalidades y vidas (ya no tan) privadas en realidades ficcionalizadas con recursos mediáticos (Sibilia, 2008: 223).

En la película Sleep Dealer Luz se intenta ganar la vida vendiendo historias como escritora, pero son narraciones testimoniales, que, precisamente, se basan en esa espectacularización del yo: en mediatizar sus propias experiencias. Luz conecta su sistema nervioso directamente al ordenador a través de un cableado, de manera que tiene una conexión biológica con la narración, y esto enfatiza el estilo testimonial y confesional del texto. Actualmente «Internet es un escenario privilegiado de este movimiento, con su proliferación de confesiones reveladas por un yo que insiste en mostrarse siempre real» (Sibilia, 2008: 22), y de ahí que podamos hablar del síndrome de Narciso $^{15}$ en las narraciones de la sociedad mediática contemporánea, donde los relatos se construyen a partir de la exhibición del autor-narrador. Luz decidió ser escritora al visitar un pueblo que no tenía nada que ver con su realidad, y quiso compartir lo que había visto; «cuento historias sobre la gente que conozco», le explica a Memo, «vendo mis memorias»:

En vez de la imaginación, la inspiración, la pericia o la experimentación que nutrían a las piezas de ficción más tradicionales, en estos casos es la trayectoria vital de quien habla $-\mathrm{y}$ en nombre de quien se habla- lo que constituye la figura del autor y lleva a legitimarlo como tal. Sin embargo, tanto esas vivencias personales como la propia personalidad del yo autoral también se ficcionalizan con ayuda de la parafernalia mediática (Sibilia, 2008: 224).

Estos recuerdos se mediatizan en el espacio digital a partir de una reconfiguración audiovisual de la experiencia narrada tal y como ofrecía la tecnología del Proyecto Brainstorm (1983, Douglas Trumbull), el Simstim de William Gibson, cuyo dispositivo permite la grabación y reproducción de las percepciones y sensaciones de los individuos en la novela Neuromante (1984) o el SQUID del film Días extraños (1995, Katheryn Bigelow). Pero en el caso de Sleep Dealer la máquina increpa al autor cuando narra y le exige decir la verdad — «por favor, di la verdad»—, ya que puede detectar el ritmo de sus pulsaciones y saber si está mintiendo debido a la conexión directa con su organismo. La literatura hipermedia de RV ofrecida por Sleep Dealer es autodiegética (y de focalización interna fija), por lo que podríamos hablar de un tipo de autobiografía documental. Philippe Lejeune en los años setenta del siglo XX entendía que las obras autobiográficas se diferenciaban del resto por el pacto de lectura que estas establecen entre el lector y el autor, asumiendo que las identidades del autor y el

\footnotetext{
${ }^{15}$ En una publicación anterior, Patologías de la realidad virtual. Cibercultura y ciencia ficción (2015), diagnosticaba cinco síntomas que podíamos detectar en la representación que se hacía en la literatura y el cine con respecto a nuestra relación con las nuevas tecnologías informáticas: esquizofrenia nominal, metástasis de los simulacros, el síndrome del cuerpo fantasma, el síndrome de Pandora y el síndrome del misticismo agudo. A estos síntomas me gustaría sumar el síndrome de Narciso, para hacer alusión a esta espectacularización del yo en las narrativas mass media, en las que se percibe una multiplicación de los reflejos textuales y audiovisuales de los neonarradores del espacio digital. Sobre el mito de Narciso véase Ovidio: Las metamorfosis (Libro III, 339-510).
} 
personaje son coincidentes En esta ocasión, el recuerdo del autor que narra se transmite de tal manera que la máquina sirve como elemento legitimador del pacto de lectura, ya que no permite mentir al narrador. Luz, como autora y personaje, se construye a través del proceso de la narración, ya que va descubriendo sus sentimientos por Memo durante el proceso de holo-escritura y las correcciones que le marca la máquina. El concepto lacaninao de la «línea de ficción», funciona en este texto, ya que el individuo trata de comprenderse, se autocensura, y se exhibe, configurando su propia identidad durante el proceso (véase Casas, 2013).

La realidad empieza a imponer sus propias exigencias: para ser percibida como plenamente real, deberá intensificarse y ficcionalizarse con recursos mediáticos. Entre las diversas manifestaciones que solicitan ese tratamiento, se destaca la vida real del autor-artista. $\mathrm{O}$ bien de ese yo que habla, que se narra y se muestra por todas partes.

La exigencia de VERDAD de la máquina al autor, nos permite reflexionar sobre cómo construimos la memoria y realizamos el montaje del pasado a través de nuestros recuerdos, y sobre cómo nos ficcionalizamos a partir de los recursos mediáticos de los que disponemos. Luz, al fin y al cabo, escoge fragmentos de sus recuerdos, monta y recorta la realidad de su memoria, y, seguramente, algo se le escapa a una máquina que no puede comprender del todo la complejidad de las sensaciones y de la mente humana. Considero pertinente comparar este tipo de narraciones autobiográficas de realidad virtual con un blog del futuro, como herramienta de autoedición a modo de diario extimista (con este término se hace alusión a la publicación de la propia intimidad a través de los mass media). Y quizás también, entraría en juego la autobiografía dialogada (ya que aparecen fragmentos de la vida de otras personas que la autora ha registrado en su sistema). Una de las características del blog se basa en que el autor se convierte en un personaje que nos transmite experiencias personales, y que el lector toma por reales - aunque en los casos de blogoficción el autor crea un personaje (un avatar) a partir del que construye un diario «falso» (véase Escandell, 2012)—. En el caso de TRUNODE tenemos constancia de que forman parte de la experiencia del autor, y lo que consume el (lecto)usuario son experiencias, fragmentos de memoria y sentimientos en $3 \mathrm{D}$ polisensoriales. Este tipo de (holo)narración comparte con la blogoficción el hecho de que el tiempo del relato parece natural, y coincide con el tiempo de escritura, por lo que «para alcanzar el nivel de verosimilitud necesario para impostar la realidad, la línea temporal de la narración debe ser simultánea a la real. La blogonovela, se construye temporalmente, por tanto, sobre el uso del presente» (Escandell, 2012: 250). La naturalidad forma parte de este tipo de escritura, y el autor/avatar y sus lectores (que hacen uso del avatar para vivir en primera persona el relato) comparten ese tiempo presente, y de ahí que el tiempo de la escritura sea más real. Tal y como sucede en un blog, los lecto-usuarios escriben al autor para conocer más detalles de los personajes sobre los que transmite sus recuerdos, y le hacen peticiones que el autor puede registrar y subir a la red.

Esta tecnología permite transmitir y hacer revivir al lecto-usuario, como si estuviera en una holocubierta, las experiencias personales del (tecno)escritor. En este caso, el avatar del autor, es poseído por el (lecto)usuario, que a través del avatar del autor, vive en primera persona las experiencias 


\section{Tropelías. Revista de Teoría de la Literatura y Literatura Comparada, 27 (2017) \\ El síndrome de Narciso y el autor como avatar postorgánico en las narrativas del futuro...}

que narra su testimonio. Por lo que el término «avatar», proveniente del hinduismo para hacer referencia a las reencarnaciones del dios Visnú, no solo tiene un valor metafórico, sino también literal, ya que el lector se encarna en el cuerpo virtualizado del autor/testimonio para sentir su relato en primera persona, y personificar diversos avatares en cada una de sus lecturas, introduciéndose en una simulación, en una hiperrealidad que sustituye el mundo real a través de intermediarios de dígitos binarios. El avatar se convierte así en una nueva prótesis del ser humano, tal y como sostiene Fernando Broncano (2009), una prótesis mediada y postorgánica a través de la que el (lecto)usuario transciende sus limitaciones físicas. Y el pacto de la (lecto)vivencia autobiográfica está garantizado. Luz piensa que las narraciones de sus recuerdos le permiten conectar a la gente: «odio que haya tanta distancia entre la gente, si los nodos sirven para algo es para romper con esa distancia, para conectarnos, para podernos ver». Y lo cierto es que este tipo de cibernarraciones intensifican los procesos de catarsis e identificación con las historias y los personajes que muestran, debido a la conexión biológica con la historia $^{16}$. Si como dice Lejeune hay un proceso de «co-autoría» en la autobiografía, ya que todo depende de la interpretación que se haga del texto, la sinceridad del autor es vital, y la creencia en esta por parte del lector también (ápud Casas, 2013), en estas memorias de realidad virtual, la sinceridad y la confianza del testimonio se experimentan en primera persona, ya que nos (holo)narran un suceso vivido en primera persona, y además, la máquina se encarga de verificar que todo es ¿real?

La ciencia ficción nos permite, a partir de la especulación, ensayar con diversas posibilidades, y en este caso, nos permite, desde dos perspectivas opuestas, pensar en el futuro de las narraciones literarias, ya sea a partir de la ficcionalización hiperrealista, o ya sea desde la exhibición de los recuerdos de la memoria, en las potencialidades artísticas que ofrece la cultura digital, la hibridación de lenguajes y la importancia de la participación del receptor en un tipo de expresión literaria que puede convivir con la literatura tradicional, y que nos habla de un futuro que ya forma parte de nuestro presente.

\section{Bibliografía}

Boullosa, Carmen: (1997): Cielos de la Tierra. México, Alfaguara.

\section{- (2006): La novela perfecta. México, Alfaguara.}

Bostrom, Nick (2003): «The Transhumanist FAQ. A General Introduction. Version 2.1.», publicado por la World Trnashumanist Association, en http://www.nickbostrom.com/views/ transhumanist.pdf (última consulta, 22-12-2016).

(2011): «Una historia del pensamiento transhumanista», Argumentos de la Razón Técnica: Revista Española de Ciencia, Tecnología y Sociedad, y Filosofía de la Tecnología, 14, pp. 157191.

\footnotetext{
${ }^{16}$ Es importante mencionar este punto, ya que Ruby compra las historias de Luz sobre Memo, y es así como conoce la historia de este personaje. Ruby era el piloto que destrozó la cabaña de la familia de Memo y asesinó a su padre y, a partir de las posibilidades empáticas que ofrece esta tecnología, abandona su trabajo en Estados Unidos y cruza la frontera para cambiar su destino.
} 
BraidotTI, Rosi (2004): Feminismo, diferencia sexual y subjetividad nómade. Barcelona, Gedisa. Brescia, Pablo (2015): «Sleep Dealer y el México del futuro: ¿borrón y cuenta nueva?», en F. SCHMIDT-Welle y C. WHER, eds., Nationbuilding en el cine mexicano desde la Época de Oro hasta el presente. Frankfurt - Madrid, Vervuert - Iberomaericana, pp. 275-282.

BRONCANO, Fernando (2009): La melancolía del ciborg. Barcelona, Herder.

Brown, J. Andrew (2010): Cyborgs in Latin America. Nueva York, Palgrave MacMillan. CASAS, Ana, comp. (2012): La autoficción. Reflexiones teóricas. Madrid, Arco Libros.

ChiAPPE, Doménico (2015): «5 retos para el escritor del futuro», 27 de septiembre, en http://www.domenicochiappe.com/5-retos-para-el-escritor-del-futuro/ (última consulta, 7-122016).

ESCANDELL, Daniel (2012): Narrativa digital hispana: el blog como espacio de creación literaria a comienzos del siglo XXI, Tesis Doctoral, Universidad de Salamanca.

_ (2013): «La impostura del avatar: la belleza intelijente de Arturo Vallejo», en Teresa LóPEZPELlisA, coord., Realidad virtual y cibercultura. Pasavento. Revista de Estudios Hispánicos, I/2, pp. 195-216.

GARCíA, Manuel Hernán (2012): «Tecnociencia y cibercultura en México: hackers en el cuento cyberpunk mexicano», en Silvia KURLAT ARES, ed., La ciencia-ficción en América Latina: entre la mitología experimental y lo que vendrá. Revista Iberoamericana, LXXVIII/238-239, pp. 392348.

JENKINS, Henry (2008): Convergence Culture. La cultura de los medios de comunicación. Barcelona, Paidós.

LÓPEZ-PELLISA, Teresa (2013): «Metástasis de los simulacros y metadiégesis digital en La novela perfecta de Carmen Boullosa», Pasavento. Revista de Estudios Hispánicos, I/2, pp. 283-296.

_ (2015): Patologías de la realidad virtual. Cibercultura y Ciencia Ficción. Madrid, Fondo de Cultura Económica.

MoRENO, Isidro (2002): Musas y nuevas tecnologías: el relato hipermedia. Barcelona, Paidós.

MurRAY, Janet (1999): Hamlet en la holocubierta: El futuro de la narrativa en el ciberespacio. Barcelona, Paidós.

RiverA, Álex (2008): Sleep Dealer. Estados Unidos, Méjico, Likely Story, Maya Entertainment.

RORTY, Richard (1990): El giro lingüístico. Barcelona, Paidós.

RYAN, Marie-Laure (2003): «Inmersión o interacción: realidad virtual y teoría literaria», en María José VEGA, Literatura hipertextual y teoría literaria. Madrid, Marenostrum, pp. 107-119.

(2004): La narración como realidad virtual. La inmersión y la interactividad en la literatura y en los medios electrónicos. Barcelona, Paidós.

SÁNCHEZ-MESA, Domingo, comp. (2004): Literatura y cibercultura. Madrid, Arco Libros.

SAVUleSCU, Julian (2012): ¿Decisiones peligrosas? Una bioética desafiante. Madrid, Tecnos.

SiBILIA, Paula (2008): La intimidad como espectáculo. Buenos Aires, Fondo de Cultura Económica. 
El síndrome de Narciso y el autor como avatar postorgánico en las narrativas del futuro...

SPIVAK, Gayatri Chakrovaorty (2003): «¿Puede hablar el subalterno?», Revista Colombiana de Antropología, 39, pp. 297-364. 